\title{
Utilization of electronic health records for the assessment of adiponectin receptor autoantibodies during the progression of cardio-metabolic comorbidities
}

Michael J. Pugia ${ }^{1 *}$, Meeta Pradhan², Rong Qi², Doreen L. Eastes ${ }^{1}$, Anna Vorsilak', Bradley J. Mills ${ }^{2}$, Zane Baird ${ }^{1}$, Aruna Wijeratne ${ }^{3}$, Scott M. McAhren ${ }^{4}$, Amber Mosley ${ }^{3}$, Anantha Shekhar ${ }^{3}$, Daniel H. Robertson ${ }^{2}$

'Bioanalytical Research Core, Indiana Biosciences Research Institute, Indianapolis IN, USA

${ }^{2}$ Applied Data Sciences Center, Indiana Biosciences Research Institute, Indianapolis IN, USA

${ }^{3}$ Indiana University School of Medicine Indianapolis IN, USA

${ }^{4}$ Eli Lilly and Company, Lilly Corporate Center, Indianapolis IN, USA

*Author for correspondence: Email:mpugia@indianabiosciences.org

Received date: August 19, 2020 Accepted date: September 02, 2020

Copyright: @ 2020 Pugia MJ, et al. This is an open-access article distributed under the terms of the Creative Commons Attribution License, which permits unrestricted use, distribution, and reproduction in any medium, provided the original author and source are credited.

\begin{abstract}
Background: Diabetes is a complex, multi-symptomatic disease whose complications drives increases in healthcare costs as the diabetes prevalence grows rapidly world-wide. Real-world electronic health records (EHRs) coupled with patient biospecimens, biological understanding, and technologies can characterize emerging diagnostic autoimmune markers resulting from proteomic discoveries.
\end{abstract}

Methods: Circulating autoantibodies for C-terminal fragments of adiponectin receptor 1 (IgG-CTF) were measured by immunoassay to establish the reference range using midpoint samples from 1862 participants in a 20-year observational study of type 2 diabetes and cardiovascular arterial disease (CVAD) conducted by the Fairbanks Institute. The White Blood Cell elastase activity in these patients was assessed using immunoassays for Bikunin and Uristatin. Participants were assigned to four cohorts (healthy, T2D, CV, CV+T2D) based on analysis of their EHRs and the diagnostic biomarkers values and patient status were assessed ten-years post-sample.

Results: The IgG-CTF reference range was determined to be $75-821 \mathrm{ng} / \mathrm{mL}$ and lgG-CTF out-ofrange values did not predict cohort or comorbidity as determined from the EHRs at 10 years after sample collection nor did IgG-CTF demonstrate a significant risk for comorbidity or death. Many patients at sample collection time had other conditions (hypertension, hyperlipidemia, or other risk factors) of which only hypertension, Uristatin and Bikunin values correlated with increased risk of developing additional comorbidities (odds ratio 2.58-13.11, $\mathrm{P}<0.05$ ).

Conclusions: This study confirms that retrospective analysis of biorepositories coupled with EHRs can establish reference ranges for novel autoimmune diagnostic markers and provide insights into prediction of specific health outcomes and correlations to other markers.

\section{Background}

Diabetes is an independent risk factor for cardiovascular arterial disease (CVAD), kidney disease, liver disease, Alzheimer's disease, and many other comorbidities, of which the costs are increasing at $>25 \%$ per year, with 380 million people likely to be affected by 2025 [1]. CVAD has the greatest economic burden, affecting one in four American adults and accounting for 6 million hospitalizations per year as well as nearly $40 \%$ of all deaths ( -17 million per year). Patients with both diabetes and CVAD exhibit significantly higher hazard ratios for additional complications than those with diabetes alone $[2,3]$.

Insulin resistance and chronic inflammation are strongly associated with the progression of metabolic syndrome and CVAD in diabetes patients [4,5]. These are complex, multi-factorial conditions and numerous biomarkers have been proposed, but few have proven effective for patient management [5]. An ideal biomarker would provide risk assessment across all individuals and accurately predict progression to various complications. However, current methods are non-specific and cannot predict progression without complex rule-in and rule-out algorithms. Although anti- 
Citation: Pugia MJ, Pradhan M, Qi R, Eastes DL, Vorsilak A, Mills BJ, et al. Utilization of electronic health records for the assessment of adiponectin receptor autoantibodies during the progression of cardio-metabolic comorbidities. Arch Autoimmune Dis 2020; 1(1):17-27.

hyperglycemic medications and standards of care for the management of weight, diet, glycosylated hemoglobin, micro-albuminuria, and albuminuria significantly reduce the risk of CVAD, there remains an urgent need to improve the health economics of diabetes [6-8].

Clinical outcome studies of diabetic complications can be long and expensive, with the death rate at $1-3 \%$ per year $[1,9]$. The cost of diagnostic marker assessment is prohibitive for relative risk analysis unless retrospective studies are used to confirm progression outcomes. Additionally, investigational assessments based on cohort comparison often introduce selection bias and cannot justify the verification and validation costs for prospective analysis [10]. Retrospective analysis also lacks real-world content because it predefines the outcome and cannot adjust for wider results. The use of electronic heath records (EHRs) provides real-world data and evidence, offering a promising and more economical method for the assessment of comorbidities, as recently shown for the prediction of chronic kidney disease [11].

Diagnostic accuracy can be improved by the detection of autoantibodies, as shown for autoantibodies against cytokines that predict autoimmune disease and tissue injury caused by autoreactive antibodies and $\mathrm{T}$ cells $[12,13]$. Autoantibodies can be quantified using anti-antigen antibodies, as shown for the adiponectin receptor C-terminal fragment (AdipoR1 $\mathrm{CTF}_{344-375}$ ) antigen, which circulates freely in the plasma of healthy individuals but not in some diabetes patients $(\mathrm{P}>0.001)$ [14]. Proteomic analysis of autoantigens is complex and difficult to translate due to the low transient concentrations $(<5 \mathrm{ng} / \mathrm{mL})$ and the need to use both stable isotope standards and monoclonal antibodies for capture [15-17]. However, once characterized, autoantigens can lead to the identification of new receptor domains, such as the highly conserved AdipoR1 $\mathrm{CTF}_{351-362}$ fragment, a strong non-competitive inhibitor of insulin-degrading enzyme (IDE) [18]. Autoantibodies can be measured routinely in human samples due to their high non-transient concentrations, including autoantibodies against AdipoR1 $\mathrm{CTF}_{344-375}$ (IgG-CTF) with a concentration range of 5-4900 $\mathrm{ng} / \mathrm{mL}$ [18].

Measuring the diagnostic significance of autoantibodies as a personalized response to disease is difficult given the long time needed for the disease to develop. However, the interaction of AdipoR1 $\mathrm{CTF}_{351-362}$ with IDE has diagnostic potential because mechanistic and drug studies have confirmed an impact of IDE on the insulin response in type 2 diabetes and CVAD [19-22]. AdipoR1, a G-protein coupled receptor, enhances glucose uptake and fatty acid oxidation in muscle, suppresses glucose output by the liver, and increases insulin sensitivity [23-26]. Low adiponectin levels predict a higher risk of type 2 diabetes and CVAD [27-35].

Autoantibodies against AdipoR1 $\mathrm{CTF}_{344-375}$ have been recently shown to develop during the onset of type 1 diabetes in the nonobese diabetic mouse model and correlated with loss of AdipoR1 signaling of AMBK in the pancreas [36]. Affected mice exhibited increased AdipoR1 shedding with marked increase of White Blood Cells in the pancreas and increased proteolytic activity, especially neutrophilic elastase [36]. The direct impact increased proteolytic activity on AdipoR1 auto antibody formation remain un-resolved. The quantification of Bikunin and Uristatin by immunoassay is a convenient means to measure any increased human neutrophilic elastase in human patients due to inflammation, infection, cardiovascular disease, and kidney diseases [37-40]. Therefore, the measurements of Bikunin and Uristatin offered an assessment of increased proteolytic activity when testing for diagnostic significance of AdipoR1 $\mathrm{CTF}_{344-375}$ autoantibodies.

The Fairbanks Institute for Healthy Communities established a biorepository comprising samples from more than 1900 Indianapolis-area type 2 diabetes and CVAD patients and controls over a 2-year period. Today, this sample bank combined with the patient's EHRs allows the analysis of novel biomarkers and their utility in predicting future diabetic complications. We assessed the levels of IgG-CTF autoantibodies, Bikunin and Uristatin in these samples of healthy controls, diabetic, and CVAD patients using the Fairbanks biorepository. These samples, in combination with realworld outcomes based on EHR data covering the subsequent 10 years post sample-collection, established IgG-CTF reference ranges and understanding of the diagnostic significance of autoantibodies for the risk of additional comorbidities.

\section{Methods}

\section{Fairbanks Institute biorepository}

The Fairbanks Institute biorepository (NCT01386801, NCT00741416) was created as an extensively annotated sample repository for hypothesis-driven research that would lead to advances in the diagnosis, treatment and prevention of diseases affecting the population of Indiana. The study was conducted in accordance with Indiana University's Internal Review Board (Protocol 1011003179: Multicenter Research Study to Build a Repository that will allow Researchers to Study Chronic Diseases in the Population of Central Indiana). All participants were 18 years or older and gave consent to provide samples.

The participants of this study were originally recruited to the type 2 diabetes cohort, CVAD cohort or healthy controls to these cohorts as defined by the criteria listed below during timeframe of sample collection (2007-2010). Study subjects in the diabetes cohort were recruited based on an EHR-confirmed history of at least one of the following: fasting blood glucose $\geq 126 \mathrm{mg} / \mathrm{dL}$ on two separate occasions; random (non-fasting) blood glucose $\geq 200 \mathrm{mg} /$ $\mathrm{dL}$ on two separate occasions; blood glucose $>200 \mathrm{mg} / \mathrm{dL}$ at $2 \mathrm{~h}$ during a standard oral glucose tolerance test; or hemoglobin A1c $(\mathrm{HbA} 1 \mathrm{c}) \geq 6.5 \%$. Study subjects in the CVAD cohort were recruited based on an EHR-confirmed history of at least one of the following: angioplasty, with or without stent placement; coronary artery bypass graft surgery; diagnostic angiogram; or positive catheterization results showing $\geq 50 \%$ occlusion. Healthy controls for the study were recruited based on having no confirmed history of any form of diabetes (as defined above) and not having a history of CVAD or other risk factors.

Biological specimens were collected from 1966 individuals ( $\mathrm{n}=724$ CVAD, $\mathrm{n}=590$ diabetes, $\mathrm{n}=652$ controls) as follows: three 10-mL EDTA tubes for plasma, $14 \mathrm{~mL}$ of urine, three $10-\mathrm{mL}$ serum separation tubes (red tops) for serum, and two 3-mL PAXgene tubes for RNA. Specimens were divided into $0.5-\mathrm{mL}$ aliquots and were stored at $-80^{\circ} \mathrm{C}$ (BioStorage Inc, Indianapolis, IN). Urine specimens were only collected from the diabetes group and half of the control subjects. Of these specimens, 1862 individuals had a complete set of samples with corresponding EHRs that could be used for biomarker assessment in this study. Table 1 details the patient demographics at the time of sample collection. 
Citation: Pugia MJ, Pradhan M, Qi R, Eastes DL, Vorsilak A, Mills BJ, et al. Utilization of electronic health records for the assessment of adiponectin receptor autoantibodies during the progression of cardio-metabolic comorbidities. Arch Autoimmune Dis 2020; 1(1):17-27.

\begin{tabular}{|c|c|c|c|c|c|}
\hline & \multirow[b]{2}{*}{ Total } & \multicolumn{4}{|c|}{ Cohorts or Affect Groups ${ }^{\mathrm{a}}$} \\
\hline & & Control & $\mathrm{T} 2 \mathrm{D}(\mathrm{no} \mathrm{CV})$ & $\mathrm{CV}(\mathrm{no} T 2 \mathrm{D})$ & $\mathrm{CV}+\mathrm{T} 2 \mathrm{D}$ \\
\hline $\mathbf{N}$ & 1862 & 733 & 427 & 344 & 358 \\
\hline \multicolumn{2}{|l|}{$\mathbf{N}$, Sample + 5yrs } & 607 & 415 & 340 & 500 \\
\hline Gender, M (\%) & $943(50.6 \%)$ & $278(37.9 \%)$ & $210(49.2 \%)$ & $245(71.2 \%)$ & $210(58.7 \%)$ \\
\hline Gender, F (\%) & 919 (49.4\%) & $455(62.1 \%)$ & $217(50.8 \%)$ & $99(28.8 \%)$ & $148(41.3 \%)$ \\
\hline Age (SD) & $56.1(9.7)$ & $54.6(9.3)$ & $54.2(9.3)$ & $58.5(9.8)$ & $59.3(9.8)$ \\
\hline Age Range & {$[22-83]$} & [34 - 82] & {$[36-82]$} & {$[30-83]$} & {$[22-82]$} \\
\hline Race, White (\%) & 1525 (81.9\%) & $551(75.2 \%)$ & $350(82.0 \%)$ & $305(88.7 \%)$ & 319 (89.1\%) \\
\hline Race, Black (\%) & $100(5.4 \%)$ & $35(4.8 \%)$ & $23(5.4 \%)$ & 15 (4.4\%) & $27(7.5 \%)$ \\
\hline Race, Other/Unknown (\%) & $237(12.7 \%)$ & 147 (20.1\%) & $54(12.6 \%)$ & 24 (7.0\%) & $12(3.4 \%)$ \\
\hline \# Deaths (\%) & $68(3.6 \%)$ & $11(1.5 \%)$ & $8(1.6 \%)$ & $15(4.4 \%)$ & 34 (9.5\%) \\
\hline Age at Death (SD) & $67.4(12.7)$ & $68.7(13.3)$ & $74.9(12.2)$ & $70.1(11.1)$ & $64.2(12.7)$ \\
\hline \multicolumn{6}{|l|}{ Medications (Filled) ${ }^{\mathrm{b}}$} \\
\hline Anti-inflammatory & 751 (40.3\%) & $251(34.2 \%)$ & $184(43.1 \%)$ & $142(41.3 \%)$ & $174(48.6 \%)$ \\
\hline Anti-hypertensive & 705 (37.9\%) & $64(8.7 \%)$ & $243(56.9 \%)$ & $184(53.5 \%)$ & $214(59.8 \%)$ \\
\hline Hyperlididemic & $510(27.4 \%)$ & $32(4.4 \%)$ & $176(41.2 \%)$ & $142(41.3 \%)$ & $160(44.7 \%)$ \\
\hline Anti-thrombotic & $62(3.3 \%)$ & $12(1.6 \%)$ & $8(1.9 \%)$ & $13(3.8 \%)$ & 29 (8.1\%) \\
\hline Glucose lowering & $461(24.8 \%)$ & $0(0.0 \%)$ & $275(64.4 \%)$ & $0(0.0 \%)$ & $186(52.0 \%)$ \\
\hline \multicolumn{6}{|l|}{ Diagnoses $^{c}$} \\
\hline Type 2 Diabetes & $644(34.6 \%)$ & $0(0.0 \%)$ & 301 (70.5\%) & $0(0.0 \%)$ & $343(95.8 \%)$ \\
\hline Cardiovascular & $702(37.7 \%)$ & $0(0.0 \%)$ & $0(0.0 \%)$ & $344(100.0 \%)$ & $358(100.0 \%)$ \\
\hline Chronic Kidney Disease & $106(5.7 \%)$ & $3(0.4 \%)$ & $12(2.8 \%)$ & $20(5.8 \%)$ & $71(19.8 \%)$ \\
\hline Liver Disease & $60(3.2 \%)$ & $4(0.5 \%)$ & $21(4.9 \%)$ & $7(2.0 \%)$ & $28(7.8 \%)$ \\
\hline Obese & 315 (16.9\%) & $30(4.1 \%)$ & $79(18.5 \%)$ & $46(13.4 \%)$ & $160(44.7 \%)$ \\
\hline Hyperlididemia & $972(52.2 \%)$ & $88(12.0 \%)$ & $239(56.0 \%)$ & 305 (88.7\%) & 340 (95.0\%) \\
\hline Hypertension & $786(42.2 \%)$ & $40(5.5 \%)$ & $184(43.1 \%)$ & $244(70.9 \%)$ & $318(88.8 \%)$ \\
\hline \multicolumn{6}{|l|}{ Diagnoses ${ }^{c}$, Sample $+5 y$ rs } \\
\hline Type 2 Diabetes & $798(42.9 \%)$ & $0(0.0 \%)$ & $323(77.8 \%)$ & $0(0.0 \%)$ & 475 (95.0\%) \\
\hline Cardiovascular & $840(45.1 \%)$ & $0(0.0 \%)$ & $0(0.0 \%)$ & 340 (100.0\%) & $500(100.0 \%)$ \\
\hline Chronic Kidney Disease & $207(11.1 \%)$ & $3(0.5 \%)$ & $20(4.8 \%)$ & 29 (8.5\%) & 155 (31.0\%) \\
\hline Liver Disease & 106 (5.7\%) & $6(1.0 \%)$ & $33(8.0 \%)$ & 14 (4.1\%) & 53 (10.6\%) \\
\hline Obese & 462 (24.8\%) & $38(6.3 \%)$ & 119 (28.7\%) & 48 (14.1\%) & 257 (51.4\%) \\
\hline Hyperlididemia & 1176 (63.2\%) & 120 (19.8\%) & 275 (66.3\%) & 300 (88.2\%) & 481 (96.2\%) \\
\hline Hypertension & 1007 (54.1\%) & $51(8.4 \%)$ & $229(55.2 \%)$ & 266 (78.2\%) & 461 (92.2\%) \\
\hline \multicolumn{6}{|c|}{$\begin{array}{l}\text { a Comparisons were made for control (unaffected) population and the affected group with type } 2 \text { diabetes (T2D), cardiovascular disease (CV) } \\
\text { or both (CV+T2D). The number of patients with the parameter and the \% of population with the parameter are shown }{ }^{\circ} \text { Diabetic medication } \\
\text { included glucose lowering and insulin. Anti-inflammatories include aspirin (ASA) and non-steroidal anti-inflammatories (NSAIDs). Lipid- } \\
\text { reducing medications include statins. Anti-hypertensives include ACE inhibitors and/or beta blockers }{ }^{\circ} \text { Clinical diagnosis based on ICD } 9 \text { and } \\
\text { ICD10 codes were used for T2D, CV, Chronic Kidney Disease (CKD), \& Liver disease (LD). A systolic BP }>140 \mathrm{mmHg} \text {, a diastolic BP }>90 \mathrm{mmHg} \text {, } \\
\text { and/or the use of anti-hypertensives defines a hypertensive patient. Patients with a value }>5 \text { and/or using lipid reducers are defined as } \\
\text { hyperlipidemic. Obesity defined as a body mass index (BMI) }>30 \text {. The number and } \% \text { for T2D, CV and CV+T2D clinical diagnosis are shown at } \\
\text { time of sample collection and } 5 \text { years from after sample collection. }\end{array}$} \\
\hline
\end{tabular}

Table 1: Patient demographics from electronic medical records at and after sample collection. 
Citation: Pugia MJ, Pradhan M, Qi R, Eastes DL, Vorsilak A, Mills BJ, et al. Utilization of electronic health records for the assessment of adiponectin receptor autoantibodies during the progression of cardio-metabolic comorbidities. Arch Autoimmune Dis 2020; 1(1):17-27.

\begin{tabular}{|c|c|c|c|c|c|}
\hline \multirow[b]{3}{*}{ Parameter $^{\mathrm{a}}$} & & Control Group & $\mathrm{T} 2 \mathrm{D}$ (no CV) & CV (no T2D) & $\mathrm{CV}+\mathrm{T} 2 \mathrm{D}$ \\
\hline & $\mathrm{N}$ & 733 & 427 & 344 & 358 \\
\hline & Units & & & & \\
\hline $\mathrm{HbA1c}$ & $\%$ & $6.03(0.55) n=50$ & $7.53(1.54) n=306^{* * *}$ & $5.80(0.37) n=73^{* *}$ & $7.40(1.67) n=271^{* * *}$ \\
\hline Fasting Glucose & $\mathrm{mg} / \mathrm{dL}$ & $80.0(6.97) n=4$ & $159.5(65.4) n=6$ & $97.3(24.3) n=5$ & $185.0(158.0) n=5$ \\
\hline Glucose & $\mathrm{mg} / \mathrm{dL}$ & $100.1(21.2) n=99$ & $172.4(69.8) n=80^{* * *}$ & $108.6(16.8) n=170^{* * *}$ & $156.3(59.3) n=228^{* * *}$ \\
\hline Diastolic Blood Pressure & $\mathrm{mmHg}$ & $73.0(11.1) n=37$ & $74.8(9.3) n=30^{*}$ & $72.4(8.5) n=74$ & $71.0(11.5) n=109$ \\
\hline Systolic Blood Pressure & $\mathrm{mmHg}$ & $123.2(17.3) n=37$ & $135.3(13.5) n=30$ & $124.5(14.9) n=74$ & $129.2(17.3) n=109$ \\
\hline Alanine Transaminase (alt) & $U / L$ & $28.7(28.5) n=58$ & $29.8(18.18) n=56$ & $29.1(14.4) n=133$ & $27.8(14.9) n=160$ \\
\hline Aspartate Transaminase (ast) & $\mathrm{U} / \mathrm{L}$ & $30.5(29.5) n=54$ & $30.4(15.6) n=53$ & $32.9(24.8) n=114$ & $35.7(47.4) n=144$ \\
\hline Direct Bilirubin & $\mathrm{mg} / \mathrm{dL}$ & $0.13(0.076) n=7$ & $0.122(0.1) n=10$ & $0.114(0.118) n=39$ & $0.112(0.072) n=7$ \\
\hline eGFR & $\mathrm{mL} / \mathrm{min} / 1.73 \mathrm{~m}^{2}$ & $66.0(17.2) n=87$ & $64.8(16.5) n=72$ & $60.7(9.82) n=159^{* *}$ & $56.4(14.8) n=211^{* * *}$ \\
\hline Total Billirubin & $\mathrm{mg} / \mathrm{dL}$ & $0.65(0.27) n=51$ & $0.56(0.31) n=49$ & $0.60(0.34) n=87$ & $0.56(0.34) n=128$ \\
\hline Albumin & $\mathrm{g} / \mathrm{dL}$ & $4.13(0.43) n=53$ & $3.91(0.57) n=51$ & $4.01(0.49) n=88$ & $3.71(0.52) n=143^{*}$ \\
\hline Creatinine & $\mathrm{mg} / \mathrm{dL}$ & $0.96(0.44) n=94$ & $0.96(0.48) n=73$ & $0.99(0.26) n=171$ & $1.17(0.74) n=221^{* *}$ \\
\hline Albumin Creatinine Ratio & $\mathrm{mg} / \mathrm{g}$ & None & $196.4(149.9) n=6$ & None & $391.6(990.2) n=23$ \\
\hline BUN & $\mathrm{mg} / \mathrm{dL}$ & $15.1(5.7) n=90$ & $16.4(8.0) n=69$ & $15.8(5.6) n=164$ & $20.4(11.2) n=218^{* * *}$ \\
\hline Total Cholesterol & $\mathrm{mg} / \mathrm{dL}$ & $182.6(34.4) n=54$ & $162.1(45.0) n=29^{*}$ & $167.0(39.8) \mathrm{n}=161^{*}$ & $164.7(45.3) n=151^{*}$ \\
\hline HDL cholesterol & $\mathrm{mg} / \mathrm{dL}$ & $54.4(18.5) n=51$ & $37.7(11.9) n=27^{* * *}$ & $42.6(12.8) n=159^{* * *}$ & $39.5(11.2) n=150^{* * *}$ \\
\hline LDL cholesterol & $\mathrm{mg} / \mathrm{dL}$ & $100.5(26.0) n=235$ & $90.4(31.7) n=282^{* * *}$ & $93.1(34.2) n=243^{* * *}$ & $87.1(33.8) n=277^{* * *}$ \\
\hline Triglycerides & $\mathrm{mg} / \mathrm{dL}$ & $117.5(67.0) n=47$ & $181.3(110.7) n=27^{* *}$ & $157.7(112.8) n=155^{*}$ & $181.2(114.9) n=147^{* *}$ \\
\hline Basophil Count & $\mathrm{k} / \mathrm{mcL}$ & $0.029(0.040) n=52$ & $0.043(0.058) n=38$ & $0.036(0.047) n=99$ & $0.039(0.047) n=130$ \\
\hline Neurophil Count & $\mathrm{k} / \mathrm{mcL}$ & $4.19(1.98) n=54$ & $5.64(3.55) n=41^{*}$ & $5.91(2.57) n=106^{* * *}$ & $5.86(2.25) n=128^{* * *}$ \\
\hline Eosinophil Count & $\mathrm{k} / \mathrm{mcL}$ & $0.164(0.117) n=53$ & $0.176(0.127) n=39$ & $0.224(0.210) n=101$ & $0.188(0.125) n=130$ \\
\hline Lymphocyte Count & $\mathrm{k} / \mathrm{mcL}$ & $1.84(0.60) n=54$ & $2.06(0.89) n=3$ & $1.96(0.90) n=105$ & $1.94(0.75) n=130$ \\
\hline Monocyte Count & $\mathrm{k} / \mathrm{mcL}$ & $134.8(54.8) n=577$ & $100.1(21.2) n=99^{* *}$ & $172.4(69.8) n=80^{*}$ & $108.6(16.8) n=170^{* * *}$ \\
\hline Platelet Count & $\mathrm{k} / \mathrm{mcL}$ & $239.4(65.4) n=86$ & $263.6(77.2) n=61^{*}$ & $237.1(70.6) n=160$ & $249.5(76.5) n=200$ \\
\hline Protein & $\mathrm{g} / \mathrm{dL}$ & $7.08(0.60) n=52$ & $7.21(0.51) n=49$ & $6.97(0.62) n=88$ & $6.88(0.73) n=130$ \\
\hline Troponin & $\mathrm{ng} / \mathrm{ml}$ & $0.013(0.021) n=10$ & $0.016(0.019) n=7$ & $0.098(0.200) n=18$ & $1.17(6.51) n=39$ \\
\hline
\end{tabular}

Table 2: Diagnostic testing obtained from electronic medical records during the patient care.

\section{Collection of EHRs}

When the Fairbanks Institute was launched, the Regenstrief Institute, Inc. (Indianapolis, IN) was responsible for providing access to the associated EHRs of the patients for research use and maintain the linkage of sample IDs to patient IDs within the Indiana Network of Patient Care (INPC) EHR repository. The Indiana Health Information Exchange is the organization responsible for collecting the EHRs into the INPC database from the participating healthcare organizations within Indiana. For the available samples, all data over 20 years was requested, including demographics, diagnosis codes, medications, clinical laboratory results, and procedures (for $\mathrm{n}=1907$ patients). No a priori filtering of the health data was requested. The data were securely delivered to the IBRI as a set of de-identified data extracts according to Health Insurance Portability and Accountability Act safe harbor rules.

\section{Initial analysis of EHR data}

EHRs were cleaned and analyzed to understand the patient disease state at sample collection by mapping diagnosis codes (ICD-9/ICD-10) to diseases. Any recorded diagnosis code prior to or within 30 days after sample collection attributed that disease to that individual at the time of sample collection. The patients 
Citation: Pugia MJ, Pradhan M, Qi R, Eastes DL, Vorsilak A, Mills BJ, et al. Utilization of electronic health records for the assessment of adiponectin receptor autoantibodies during the progression of cardio-metabolic comorbidities. Arch Autoimmune Dis 2020; 1(1):17-27.

and control diagnosis codes were reassessed 5 years after sample collection (Table 1). The number of medications was computed by mapping the National Drug Code to pharmaceutical class using the National Library of Medicine RxNorm [41]. Due to the variability in duration of prescriptions, a prescription was counted if filled 180 days before or after sample collection. Finally, the clinical variables from the EHRs were normalized relative to names and units of measures, outliers removed, and values computed for each patient as the mean of values within 180 days of the sample collection date.

Diagnostic testing performed during patient care after sample collection was obtained from the EHRs and matched with the demographics for $(n=1847)$ patients and controls who remained in the system (Table 2). Because real-world can be incomplete, not all data was available for each diagnostic test or individual. The absence of data does not necessarily mean the absence of the condition, so the data in Table 2 are considered minimum values. Clinical parameters with fewer than 10 patients per group were discarded due to lack of data. Means and standard deviations were used from the total sum of results for each patient and across the available records.

\section{Statistical Analysis of EHRs}

The affected groups were compared to the control groups for all EHR diagnostic measurements $(n=1847)$ (Table 2). For this study, based on EHR analysis, the patients were assigned to one of four cohorts at the time of sample collection, regardless of their original cohort assigned from the Fairbanks study designation: Control Group, Type 2 Diabetes (T2D), Cardiovascular (CV), and Type 2 Diabetes and Cardiovascular $(\mathrm{CV}+\mathrm{T} 2 \mathrm{D})$. The $\mathrm{p}$ value for differences between the affected and control groups was calculated using the normal approximation to the binomial distribution with continuity correction. For quantitative factors (e.g. age and diagnostic tests), the count, mean, standard deviation, minimum and maximum values, and calculated $\mathrm{p}$ values were determined for differences between group means assuming a $t$-distribution. Before calculating the $t$-value, the group standard deviations were compared using the F distribution. The clinical variables associated with the cohorts defined in Table 1 were analyzed to understand their significance within and across the cohorts. To understand the significance of the variable with respect to each cohort, between cohorts and across cohorts, the data were processed by univariate and bivariate analysis and ANOVA. Each variable was analyzed for significance across cohorts using an independent samples $t$-test. Table 2 shows the significant $p$ values for each variable. Differences between the affected and control groups were deemed statistically significant if the corresponding $\mathrm{p}$ values were less than 0.001 (99.9\%), 0.01 (99\%) or $0.05(95 \%)$.

\section{Analysis of EHR outcomes}

The EHRs of total patients $(\mathrm{n}=1847)$ and cohorts were assessed for disease indications and the presence of hypertension (HT) and/ or hyperlipidemia (HLD) prior to sample collection. The subsequent development of comorbidities was assessed by EHR data analysis to confirm the development of type 2 diabetes (T2D) $(n=174)$, cardiovascular (CV) $(\mathrm{n}=140)$, chronic kidney disease (CKD, $\mathrm{n}=136$ ), or liver disease (LD, $\mathrm{n}=53$ ). The development of multiple comorbidities such as CV+T2Ds $(n=39)$, T2D+CKD $(n=32)$, T2D+LD ( $n=10)$, and CV+CKD ( $n=29)$ was also recorded. The disease progression from initial sample collection to final outcome based on available EHR data is depicted in the Sankey flow diagram (Figure 1). Additional phenotypes combining more than two comorbidities represented less than $0.7 \%$ of the patients and their significance could not be assessed.

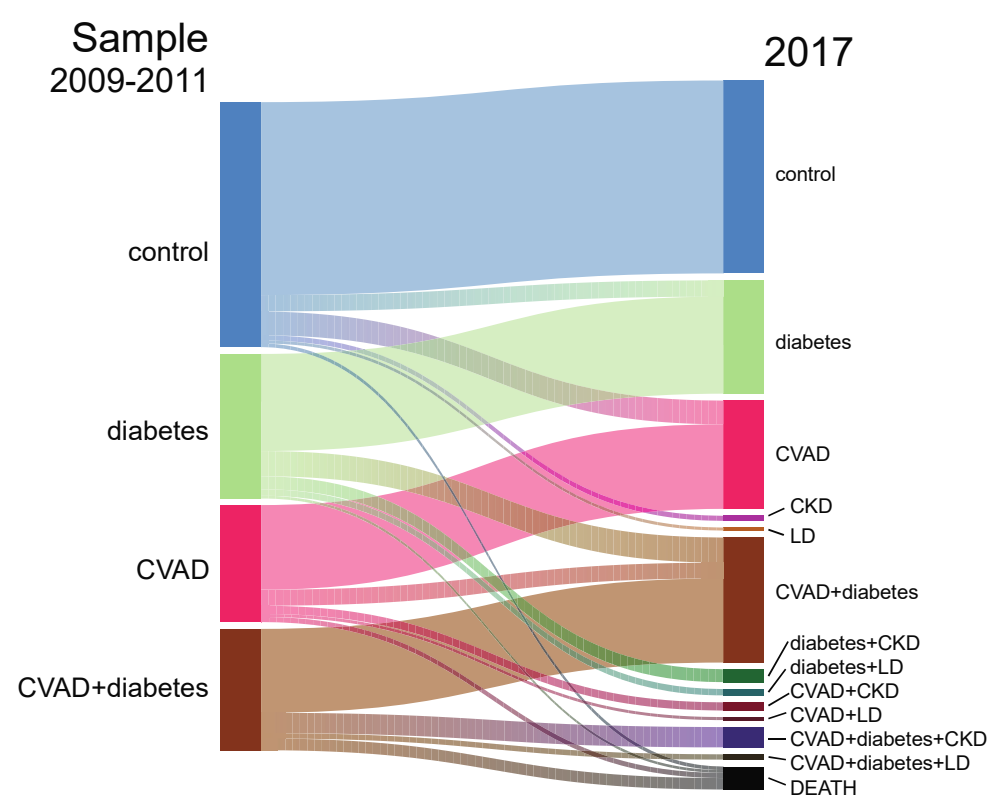

Figure 1: Sankey flow diagram showing the transition from initial disease state at sample collection to final outcome based on EHR data for the 1847 patients. The bars represent the number of individuals within that disease state and the width of the connections represents that number of the individuals transitioning to the new final state after sample collection. The number of individuals with hypertension alone, hyperlipidemia alone, or both, was also computed for these cohorts at sample collection but the data are not shown. These numbers are for the control $(29,78,39)$, diabetesT2D $(28,82,182)$, CVAD-CV $(16,77,242)$ and CV+diabetes/CV+T2D $(14,37,315)$ cohorts, respectively. 
Citation: Pugia MJ, Pradhan M, Qi R, Eastes DL, Vorsilak A, Mills BJ, et al. Utilization of electronic health records for the assessment of adiponectin receptor autoantibodies during the progression of cardio-metabolic comorbidities. Arch Autoimmune Dis 2020; 1(1):17-27.

peptide) calibrator taken to represent the elastase cleavage site and isotope label internal standard (Celtek Biosciences, Franklin, TN) to quantify down to limit of quantitation of 50 fmoles (Proteomic Core Procedure IU School of Medicine). Additionally, western blot analysis of plasma samples confirmed IgG-CTF as the key bound forms by the presence of gamma heavy chains $(50-55 \mathrm{kDa})$ and kappa light chains $(26-28 \mathrm{kDa})$ but a lack significant direct attachment to other proteins as previously reported [14].

The presence of any infection or inflammation as indicated by elastase release of Bikunin and Uristatin (Table 3) was determined for all available urine samples $(n=663)$ collected only from the T2D cohort and all available plasma samples $(n=1713)$ by enzymelinked immunosorbent assay (ELISA) as previously described [37]. Samples were thawed to room temperature, $10 \mu \mathrm{L}$ was transferred to duplicate lanes of a polypropylene sample plate, diluted and assayed as previously described [37]. The plate was stored at $4{ }^{\circ} \mathrm{C}$ for testing within $24 \mathrm{~h}$ or at $-80^{\circ} \mathrm{C}$ for future testing (up to 5 years).

\section{Comorbidity statistical analysis}

Odds ratios were calculated to compare patients with new disease from those with unchanged clinical profiles when abnormal biomarkers, HT or HLD were present. The morbidity for all cases was determined $(n=68)$ and used to calculate survival odds ratios. Patients developing T2D, CV, CKD or LD comorbidities at any time after sample collection were considered as the combined group of patients who progressed to additional comorbidities. Patient deaths were assessed across all four patient groups for sample sizes above $n=10$. The significance of odds ratios was estimated using standard error for the odds ratios was based on the sample size.

\section{Results}

\section{Participant characteristics}

Patients were equally represented in terms of gender $(-50 \%)$ and initial disease groupings $(-20 \% \mathrm{~T} 2 \mathrm{D}, \mathrm{CV}$ and CV+T2D) (Table 1$)$. Age (30s to 80 s) and race (80\% white) were also consistent across the groups. Medications were consistent with expected standards of care. The proportion of patients with T2D, CV and CV+T2D increased significantly in the 5 years post sample collection (Table 1).

\section{Laboratory Measurements}

The types of diagnostic tests used in this study agreed with the standards of care that would be expected for patients with T2D and CV over this study period. Most patients had multiple tests for key monitors such as glucose, complete blood cell count, lipid panels, and kidney function. The additional measurements indicated the correlation between parameters and conditions are shown in Table 2. Fasting blood glucose levels and HbA1c were elevated for T2D but not CV patients. The spot glucose ranges were significantly elevated for T2D and only slightly elevated for CV patients. The kidney function results based on estimated glomerular filtration rate (eGFR) values were significantly worse for CV patients but not T2D patients. Only the CV and diabetes groups had higher mean blood urea nitrogen (BUN) values, lower serum creatine, and lower plasma albumin as expected given the worse renal conditions. Microalbuminuria testing (albumin/creatine ratio) was measured too rarely to be significantly assessed in the EHR data.

The mean neutrophil counts were significantly elevated in both T2D and CV patients. Monocyte counts were lower in T2D and higher in CV patients. Total lipids, LDL, and HDL were significantly lower in T2D and CV patients compared to controls (patients were generally on lipid-lowering medications). Blood pressure ranges showed no significant differences. Triglyceride levels were highest in T2D patients followed by CV patients and were consistently higher than the control group.

\section{New biomarker testing}

The observed reference range of IgG-CTF was 75-821 ng/ $\mathrm{mL}$ (mean $237 \mathrm{ng} / \mathrm{mL}$, standard deviation 156) with $2.5 \%$ of participants exhibiting elevated autoantibodies (821-7892 $\mathrm{ng} / \mathrm{mL})$ and $11 \%$ lacking autoantibodies $(<75 \mathrm{ng} / \mathrm{mL})$. No significant differences were observed between control group, $\mathrm{T} 2 \mathrm{D}, \mathrm{CV}$, and $\mathrm{CV}+\mathrm{T} 2 \mathrm{D}$ cohorts when autoantibodies were absent (all groups, 2.9-5.1\%) or present at elevated levels (all groups, $0.4-0.9 \%$ ) (Table 3).

Uristatin immunoassay urine values ranged from 0.1 to 278.9 $\mathrm{mg} / \mathrm{L}$, with $84 \%$ of the patients within the normal range $<7.5$ $\mathrm{mg} / \mathrm{L}$ at sample collection (Table 3-B). The $98 \%$ reference range of $<7.5 \mathrm{mg} / \mathrm{L}$ for normal results was previously determined for 6292 patients lacking infection, inflammation or kidney disease (37-40). In $19 \%$ samples $(n=127)$ the level of Uristatin was $\geq 7.5$ $\mathrm{mg} / \mathrm{L}$. The mean values did not differ significantly between the control, T2D, and CV+T2D cohorts. Elevated Uristatin values $(\geq 7.5 \mathrm{mg} / \mathrm{L})$ were observed in all groups.

Bikunin immunoassay plasma values ranged from 0.0 to $2.43 \mu \mathrm{g} / \mathrm{mL}$. Previously we reported $94 \%$ of the CV patients and $97 \%$ of metabolic syndrome patients have Bikunin values in the normal range of $<1.4 \mu \mathrm{g} / \mathrm{mL}$ ( $\mathrm{n}=188$ patients) [40]. In agreement, we found the $93 \%$ of the 1932 patients here had values of $<1.4 \mu \mathrm{g} / \mathrm{mL}$ (Table $3-\mathrm{C}$ ). The mean values did not differ significantly between patient groups and elevated Bikunin $\geq 1.4 \mu \mathrm{g} / \mathrm{mL}$ (7\%, $\mathrm{n}=119$ patients) was observed in all groups (control group, CV and T2D).

\section{Diagnostic phenotyping and impact}

The highest mortality rates $(9.5 \%$ over 10 years) were observed for T2D patients who progressed to CV followed by CV-only patients $(4.4 \%)$ while the mortality rates for T2D patients who developed no comorbidities (1.9\%) and control group $(1.5 \%)$ were significantly lower over the same 10 -year period (Table 4). For the control group cohort, the most likely new comorbidities were CV (9.7\%), T2D (6.7\%), CKD (2.1\%) and LD (1.2\%). For the CV cohort, the most likely new comorbidities were diabetes (13.7\%), CKD (7.0\%) and LD (2.6\%). For the T2D cohort, the most likely new comorbidities were CV (17.4\%), CKD (8.9\%) and LD (4.5\%). For the $\mathrm{CV}+\mathrm{T} 2 \mathrm{D}$ cohort, the most likely new comorbidities were CKD (16.8\%) and LD (4.5\%).

Using only the statistically significant results from Table 4, patients with HT in the Control Group and CV cohorts were found to be more likely to develop new comorbidities (odds ratio 4.36-5.34). Additionally, T2D patients positive for HLD appear to have delayed progression to comorbidities, but overall 
Citation: Pugia MJ, Pradhan M, Qi R, Eastes DL, Vorsilak A, Mills BJ, et al. Utilization of electronic health records for the assessment of adiponectin receptor autoantibodies during the progression of cardio-metabolic comorbidities. Arch Autoimmune Dis 2020; 1(1):17-27.

any individual positive with HLD showed increased likelihood of death. Elevated uristatin $(\geq 7.5 \mathrm{mg} / \mathrm{L})$ showed no significant likelihood to progress to new comorbidities across any cohorts (Table 4-A). Patients lacking IgG-CTF $(\leq 75 \mathrm{ng} / \mathrm{mL})$ were no more likely to progress to comorbidities (odds ratio $0.73-1.48$ ) than those with elevated IgG-CTF $(\geq 821 \mathrm{ng} / \mathrm{mL}$ ) (odds ratio 0.87 to 1.93 ) (Table 4-A). However, there were no observations within this study of anyone with elevated IgG-CTF progressing to death and lowered IgG-CTF showed increased odds ratio for risk of death, but the $\mathrm{p}$ value as only at $93 \%$ confidence interval. In this study, due to lack of observations we cannot place statistical significance on either of these odds ratios and a larger study would be needed to confirm this protective nature of elevated IgG-CTF or the increased risk to death from lowered Ig-CTF (Table 4-A). T2D patients with elevated Uristatin $(>7.5 \mathrm{mg} / \mathrm{L})$ and $\mathrm{CV}$ patients with elevated Bikunin $(>1.4 \mu \mathrm{g} /$ $\mathrm{mL}$ ) were both more likely to progress to comorbidities with significant odds ratios of 13.11 and 4.44, respectively (Table 4-B).

A. Odds ratios for patient progression to any additional co-morbidities for patients with high blood pressure, hyperlipidema and biomarkers outside of reference ranges. Most are not statistically significant due to small number of observations, but for those that are statistically significant are shown by the number of asterisks.

\begin{tabular}{|c|c|c|c|c|c|c|c|}
\hline & & $\begin{array}{l}\text { Uristatin } \\
\geq 7.5 \mathrm{mg} / \mathrm{L}\end{array}$ & $\begin{array}{l}\text { Bikunin } \\
\geq 1.4 \mathrm{mg} / \mathrm{L}\end{array}$ & HT & HLD & $\begin{array}{l}\text { lgG-CTF } \\
\leq 75 \mathrm{ng} / \mathrm{mL}\end{array}$ & $\begin{array}{l}\lg G \text { CTF } \\
\geq 821 \mathrm{ng} / \mathrm{mL}\end{array}$ \\
\hline \multirow[t]{3}{*}{ Control Group } & Odds ratio & 1.42 & 0.58 & $2.78^{* *}$ & 1.07 & 1.26 & 1.20 \\
\hline & $\mathrm{n}$ (all tested) & 320 & 653 & 722 & 721 & 686 & 686 \\
\hline & $\mathrm{n}$ (all progressing) $^{+}$ & 40 & 105 & 117 & 117 & 111 & 111 \\
\hline \multirow[t]{3}{*}{ CV (no T2D) } & Odds ratio & NS & 1.2 & $2.06^{* *}$ & 0.56 & 1.05 & 0.88 \\
\hline & $\mathrm{n}$ (all tested) & 7 & 326 & 344 & 344 & 343 & 343 \\
\hline & $\mathrm{n}$ (all progressing) ${ }^{+}$ & 2 & 68 & 69 & 69 & 69 & 69 \\
\hline \multirow[t]{3}{*}{ T2D (no CV) } & Odds ratio & 1.23 & 1.95 & 0.75 & $0.39 * * *$ & 1.48 & 1.93 \\
\hline & $\mathrm{n}$ (all tested) & 380 & 391 & 425 & 425 & 403 & 403 \\
\hline & $\mathrm{n}$ (all progressing) ${ }^{\dagger}$ & 116 & 135 & 144 & 144 & 139 & 139 \\
\hline \multirow[t]{3}{*}{$\mathrm{CV}+\mathrm{T} 2 \mathrm{D}$} & Odds ratio & 0.54 & 0.53 & 1.77 & 2.47 & 0.73 & 0.87 \\
\hline & $\mathrm{n}$ (all tested) & 83 & 341 & 357 & 357 & 351 & 351 \\
\hline & $\mathrm{n}$ (all progressing) ${ }^{\dagger}$ & 15 & 75 & 78 & 78 & 78 & 78 \\
\hline \multirow[t]{3}{*}{ Death } & Odds ratio & 1.04 & 1.50 & $5.54^{*}$ & $2.78^{* * *}$ & 1.87 & 0.0 \\
\hline & $\mathrm{n}$ (all tested) & 792 & 1713 & 1849 & 1849 & 1785 & 1785 \\
\hline & $\mathrm{n}$ (all progressing) ${ }^{\dagger}$ & 18 & 60 & 67 & 67 & 61 & 61 \\
\hline
\end{tabular}

B. Additional significant $(\mathrm{p}$ value $<0.05$ ) odds ratios for transitions from initial cohort condition to additional states

\begin{tabular}{|c|c|c|c|c|c|}
\hline Biomarker Condition & Cohort & Post-Sample State & Odds Ratio & $\mathrm{n}$ (all tested) & $\mathrm{n}$ (all progressing) \\
\hline Hypertension - HT & Control Group & $C V$ (no T2D) & $2.58^{*}$ & 722 & 70 \\
\hline Hypertension - HT & Control Group & Liver Disease & $9.39 * *$ & 722 & 9 \\
\hline Hypertension - HT & T2D (no CV) & Death & $8.25^{*}$ & 425 & 144 \\
\hline Uristatin $\geq 7.5 \mathrm{mg} / \mathrm{L}$ & T2D (no CV) & CV+Liver Disease & $13.11^{*}$ & 425 & 5 \\
\hline Hyperlipidemia - HLD & CV (no T2D) & Chronic Kidney Disease & $0.37^{*}$ & 344 & 24 \\
\hline Bikunin $\geq 1.4 \mathrm{mg} / \mathrm{L}$ & CV (no T2D) & Death & $4.45^{*}$ & 344 & 15 \\
\hline \multicolumn{6}{|c|}{$\begin{array}{l}{ }^{+} \text {Patients who developed diabetes, cardiovascular disease (CVAD), chronic kidney disease (CKD) or liver disease (LD) any time after sampling were } \\
\text { considered as the combined group of patients progressing to comorbidities. Patient deaths in all four patient groups were combined to allou } \\
\text { significance testing. NS = not suitable for significance testing due to sample size (CVAD urine samples, only } n=7) \text {. } \\
{ }^{*} \text { p values of } 95 \% \text { significance. }{ }^{* *} \text { p values of } 99 \% \text { significance. }{ }^{* * *} \text { p values of } 99.9 \% \text { significance }\end{array}$} \\
\hline
\end{tabular}

Table 4: Prediction of additional co-morbidities. 
Citation: Pugia MJ, Pradhan M, Qi R, Eastes DL, Vorsilak A, Mills BJ, et al. Utilization of electronic health records for the assessment of adiponectin receptor autoantibodies during the progression of cardio-metabolic comorbidities. Arch Autoimmune Dis 2020; 1(1):17-27.

\section{Conclusions}

Autoantibody discoveries offer a new generation of potential biomarkers to characterize a wider range of post-translational modifications caused by stress on cells and tissues prior to the development of a diagnosed autoimmune pathology. These methods allow direct observations from human specimens that can uncover unique fragments with biological responses. The discovery of the adiponectin receptor binding to IDE results was directly from the proteomic analysis of the AdipoR1 CTF in plasma [14]. Circulating autoantibodies recognizing this fragment (IgG-CTF) appear in most human and animal blood and were measurable by ELISA in all patients included in this study [18]. No significant differences in IgG-CTF values in the diabetes or CVAD disease groups were found compared to healthy controls, which is in agreement with earlier results [18].

The presences or absence of IgG-CTF autoantibodies also did not correlate significantly with accelerated progression to T2D and $\mathrm{CV}$ but correlated to lower risk of mortality. These findings suggest that IgG-CTF autoantibodies have general neutralizing function, potentially eliminating the ability of CTF peptides to inhibit IDE in the blood. Verification of this new autoantigen in human blood is difficult to translate because the CTF binds other molecules and is only transiently present at very low concentrations, making reproducible measurements difficult to achieve in patient samples [18]. However, the measurement of autoantibodies recognizing this proteolytic fragment could potentially indicate receptor turnover due to disease stress early in a patient's clinical course. Patients on therapies inhibiting release of Tumor Necrosis Factor TNF $\alpha$ have been shown to have suppressed IgG-CTF autoantibodies while some cancer and liver disease patients have elevated values [18].

Autoantibody responses can be measured in patients over longer periods of time without seeing significant change. Previous studies showed no variation in the levels of IgG-CTF over 90 days in samples from patients without significant weight change [18]. Further work is necessary to understand the development and loss of these autoantibodies during disease. In this study, age, sex, and race did not significantly affect IgG-CTF values in patients and it also agrees with previous findings that autoantibodies in diabetes and control subjects did not correlate with diabetes progression as measured by impaired fasting glucose or impaired glucose tolerance [18]. Although IgG-CTF values do not change following glucose administration (GGTT), the free CTF autoantigen does change during the subsequent $120 \mathrm{~min}$ in animal models suggesting a biological role [18].

Hypertension was the expected other predictor of progression in this population and the EHR data confirmed this significant factor. Additionally, elevated levels of Bikunin and Uristatin due to inflammatory white blood cell elastase were very common in these patients $(22 \%)$ and did predict increased risk of the development of comorbidities $(\mathrm{P}>0.05)$ in specific subsets of patients. Bikunin and Uristatin immunoassay values are typically within the normal range for the diabetic and cardiovascular population in the absence of infection, inflammation, tissue injury or kidney disease (38-40). The lack of correlation between increased white blood cell elastase and IgG-CTF values was not surprising as autoantibodies could result from multiple tissue locations, proteolytic events and normal receptor turn over. Additional work on the causes of IgG-CTF values outside of the reference range is needed to identify the value this marker.

This study confirms that retrospective analysis of biorepositories using EHR-based outcomes can provide insight into the role of autoantibodies to proteolytic fragments of cell receptors. Autoantibodies immunoassays provide stable measurements and avoid the problems of measuring transient autoantigens. A highlymultiplexed panel of antibodies covering a wide range of receptor fragments could potentially detect higher receptor turnover in tissues as a more comprehensive multi-factorial receptor response during disease. Genetic blood assays often cannot resolve signals from the post-translational fragmentation of receptors. Here, autoimmune assays may help to resolve phenotypic expression profiles in tissues that cannot be investigated by blood gene testing.

\section{Acknowledgments}

The authors acknowledge the Regenstrief Institute, Inc. and the Indiana Clinical Translational Sciences Institute for access to the deidentified patient records corresponding to the collected biological specimens. The authors acknowledge BioCrossroads, Troy Hege, and Natalie Stull for the stewardship of the biorepository and transfer for testing. Additionally, we thank our undergraduate intern from IUPUI, Mona Bhattrai, who performed the cell culture for materials for research-use antibodies.

\section{Funding}

This work was supported by funding to the Indiana Biosciences Research Institute provided by the State of Indiana, Lilly Endowment, Eli Lilly and Company, Roche Diagnostics, Corteva Agriscience (formerly Dow AgroSciences), Indiana University Health, and Indiana University School of Medicine. This publication was made possible, in part, with support from the Fairbanks Institute for Healthy Communities funded by the Richard M. Fairbanks Foundation, as well as the Indiana Clinical and Translational Sciences Institute funded partially by Grant Number TR000006 from the National Institutes of Health, National Center for Advancing Translation Sciences, Clinical and Translational Sciences Award.

\section{Duality of Interest}

This work was supported by funding to the Indiana Biosciences Research Institute as a non-profit independent research entity with no reported potential conflicts of interest relevant to this article.

\section{Author Contributions}

M.J.P. contributed to the study design, new marker testing, data analysis, discussion, the acquisition of study support, manuscript writing, editing and review, and the creation of study protocols. D.R. contributed to the study concept, the acquisition of study support, the design, data analytics, the security of the medical records, and manuscript writing and review. M.P., R.Q., B.M., and S.M. recovered and verified the clinical and diagnostic data from the EHRs, performed data analysis, and reviewed and edited the manuscript. D.E. and A.V. collected ELISA data and reviewed the manuscript. Z.B., A.W. and A.M. performed isolation, proteomics, and reviewed and edited the manuscript. A.S. was the Principal Investigator of the Multicenter Research Study to Build a Repository to Study Chronic Diseases in Indiana (IHS) that built the repository. D.R. and M.J.P. are the guarantors of this work and, as such, had 
Citation: Pugia MJ, Pradhan M, Qi R, Eastes DL, Vorsilak A, Mills BJ, et al. Utilization of electronic health records for the assessment of adiponectin receptor autoantibodies during the progression of cardio-metabolic comorbidities. Arch Autoimmune Dis 2020; 1(1):17-27.

full access to all the data in the study and take responsibility for the integrity of the data and the accuracy of the data analysis.

\section{References}

1. Susan van D, Beulens JW, Yvonne T. van der S, Grobbee DE, Nealb B. The global burden of diabetes and its complications: an emerging pandemic. European Journal of Cardiovascular Prevention \& Rehabilitation. 2010 May;17(1_suppl):s3-8.

2. Laakso M. Cardiovascular disease in type 2 diabetes from population to man to mechanisms: the Kelly West Award Lecture 2008. Diabetes care. 2010 Feb 1;33(2):442-9.

3. An $D$, Rodrigues B. Role of changes in cardiac metabolism in development of diabetic cardiomyopathy. American Journal of Physiology-Heart and Circulatory Physiology. 2006 Oct;291(4):H1489-506.

4. Rask-Madsen C, Kahn CR. Tissue-specific insulin signaling, metabolic syndrome, and cardiovascular disease. Arteriosclerosis, Thrombosis, and Vascular Biology. 2012 Sep;32(9):2052-9.

5. Abel ED, O'Shea KM, Ramasamy R. Insulin resistance: metabolic mechanisms and consequences in the heart. Arteriosclerosis, Thrombosis, and Vascular Biology. 2012 Sep;32(9):2068-76.

6. Mukamal KJ, Siscovick DS, de Boer IH, Ix JH, Kizer JR, Djoussé L, et al. Metabolic clusters and outcomes in older adults: the cardiovascular health study. Journal of the American Geriatrics Society. 2018 Feb;66(2):289-96.

7. Nathan DM. for the Diabetes Control and Complications Trial/ Epidemiology of Diabetes Interventions and Complications (DCCT/ EDIC) study research group. Intensive diabetes treatment and cardiovascular disease in patients with type 1 diabetes. The New England Journal of Medicine. 2005;353:2643-53.

8. Packer M. Contrasting effects on the risk of macrovascular and microvascular events of antihyperglycemic drugs that enhance sodium excretion and lower blood pressure. Diabetic Medicine. 2018 Jun;35(6):707-13.

9. Emerging Risk Factors Collaboration. Diabetes mellitus, fasting glucose, and risk of cause-specific death. New England Journal of Medicine. 2011 Mar 3;364(9):829-41.

10. Holman RR, Sourij H, Califf RM. Cardiovascular outcome trials of glucose-lowering drugs or strategies in type 2 diabetes. The Lancet. 2014 Jun 7;383(9933):2008-17.

11. Ravizza S, Huschto T, Adamov A, Böhm L, Büsser A, Flöther FF, et al. Predicting the early risk of chronic kidney disease in patients with diabetes using real-world data. Nature Medicine. 2019 Jan;25(1):579.

12. Rose NR, Mackay IR, Eds. The Autoimmune Diseases. 5th ed. Amsterdam, Netherlands, Elsevier, 2014.

13. Leslie D, Lipsky $P$, Notkins AL. Autoantibodies as predictors of disease. The Journal of Clinical Investigation. 2001 Nov 15;108(10):1417-22

14. Pugia MJ, Franke DD, Barnes SL, Zercher A, Brock D, Foltz M, et al. Adiponectin receptor-1 C-terminal Fragment (CTF) in plasma: putative biomarker for diabetes. Clinical Proteomics. 2009 Dec 1;5(3-4):156-62.

15. Anderson NL, Anderson NG, Haines LR, Hardie DB, Olafson RW, Pearson TW. Mass spectrometric quantitation of peptides and proteins using Stable Isotope Standards and Capture by AntiPeptide Antibodies (SISCAPA). Journal of Proteome Research. 2004 Apr 12;3(2):235-44.
16. Anderson NL, Razavi M, Pearson TW, Kruppa G, Paape R, Suckau D. Precision of heavy-light peptide ratios measured by MALDITOF mass spectrometry. Journal of Proteome Research. 2012 Mar 2;11(3):1868-78.

17. Camenzind AG, van der Gugten JG, Popp R, Holmes DT, Borchers CH. Development and evaluation of an immuno-MALDI (iMALDI) assay for angiotensin I and the diagnosis of secondary hypertension. Clinical Proteomics. 2013 Dec;10(1):1-9.

18. Pugia MJ, Ma R, Vella A. Role of C-terminal fragment of adiponectin receptor in inhibition of insulin degradation. Part 3 In Inflammatory Pathways in Diabetes: Biomarkers and Clinical Correlates. Pugia MJ, Ed. Cham, Switzerland, Springer, 2015, 61-111.

19. Maianti JP, McFedries A, Foda ZH, Kleiner RE, Du XQ, Leissring MA, et al. Anti-diabetic activity of insulin-degrading enzyme inhibitors mediated by multiple hormones. Nature. 2014 Jul;511(7507):94-8.

20. Leissring MA, Malito E, Hedouin S, Reinstatler L, Sahara T, AbdulHay SO, et al. Designed inhibitors of insulin-degrading enzyme regulate the catabolism and activity of insulin. PloS One. 2010 May 7;5(5):e10504.

21. Duckworth WC, Bennett RG, Hamel FG. Insulin degradation: progress and potential. Endocrine Reviews. 1998 Oct 1;19(5):60824.

22. Abdul-Hay SO, Kang D, McBride M, Li L, Zhao J, Leissring MA. Deletion of insulin-degrading enzyme elicits antipodal, agedependent effects on glucose and insulin tolerance. PloS One. 2011 Jun 9;6(6):e20818.

23. Yamauchi T, Kamon J, Minokoshi YA, Ito $Y$, Waki $H$, Uchida $S$, et al. Adiponectin stimulates glucose utilization and fatty-acid oxidation by activating AMP-activated protein kinase. Nature Medicine. 2002 Nov;8(11):1288-95.

24. Yamauchi T, Kamon J, Ito $Y$, Tsuchida A, Yokomizo T, Kita S, et al. Cloning of adiponectin receptors that mediate antidiabetic metabolic effects. Nature. 2003 Jun;423(6941):762-9.

25. Kadowaki T, Yamauchi T, Kubota N, Hara K, Ueki K, Tobe K. Adiponectin and adiponectin receptors in insulin resistance, diabetes, and the metabolic syndrome. The Journal of Clinical Investigation. 2006 Jul 3;116(7):1784-92.

26. Zhou L, Deepa SS, Etzler JC, Ryu J, Mao X, Fang Q, et al. Adiponectin activates AMP-activated protein kinase in muscle cells via APPL1/ LKB1-dependent and phospholipase $\mathrm{C} / \mathrm{Ca} 2+/ \mathrm{Ca} 2+/$ calmodulindependent protein kinase kinase-dependent pathways. Journal of Biological Chemistry. 2009 Aug 14;284(33):22426-35.

27. Shibata R, Ouchi N, Ito M, Kihara S, Shiojima I, Pimentel DR, et al. Adiponectin-mediated modulation of hypertrophic signals in the heart. Nature Medicine. 2004 Dec;10(12):1384-9.

28. Daimon M, Oizumi T, Saitoh T, Kameda W, Hirata A, Yamaguchi H, et al. Decreased serum levels of adiponectin are a risk factor for the progression to type 2 diabetes in the Japanese Population: the Funagata study. Diabetes Care. 2003 Jul 1;26(7):2015-20.

29. Pischon T, Girman CJ, Hotamisligil GS, Rifai N, Hu FB, Rimm EB. Plasma adiponectin levels and risk of myocardial infarction in men. Jama. 2004 Apr 14;291(14):1730-7.

30. Pischon T, Hu FB, Girman CJ, Rifai N, Manson JE, Rexrode KM, et al. Plasma total and high molecular weight adiponectin levels and risk of coronary heart disease in women. Atherosclerosis. $2011 \mathrm{Nov}$ 1;219(1):322-9.

31. Laughlin GA, Barrett-Connor E, May S, Langenberg C. Association of adiponectin with coronary heart disease and mortality: the 
Citation: Pugia MJ, Pradhan M, Qi R, Eastes DL, Vorsilak A, Mills BJ, et al. Utilization of electronic health records for the assessment of adiponectin receptor autoantibodies during the progression of cardio-metabolic comorbidities. Arch Autoimmune Dis 2020; 1(1):17-27.

Rancho Bernardo study. American Journal of Epidemiology. 2007 Jan 15;165(2):164-74.

32. Kumada $M$, Kihara $S$, Sumitsuji $S$, Kawamoto $T$, Matsumoto $S$, Ouchi N, Arita Y, Okamoto Y, Shimomura I, Hiraoka H, Nakamura T. Association of hypoadiponectinemia with coronary artery disease in men. Arteriosclerosis, thrombosis, and vascular biology. 2003 Jan 1;23(1):85-9.

33. Nakamura Y, Shimada K, Fukuda D, Shimada Y, Ehara S, Hirose M, et al. Implications of plasma concentrations of adiponectin in patients with coronary artery disease. Heart. 2004 May 1;90(5):528-33.

34. Sattar N, Wannamethee G, Sarwar N, Tchernova J, Cherry L, Wallace A, et al. Adiponectin and coronary heart disease: a prospective study and meta-analysis. Circulation. 2006 Aug 1;114(7):623-9.

35. Wang Y, Lam KS, Xu JY, Lu G, Xu LY, Cooper GJ, et al. Adiponectin inhibits cell proliferation by interacting with several growth factors in an oligomerization-dependent manner. Journal of Biological Chemistry. 2005 May 6;280(18):18341-7.

36. Frabutt D, Stull N, Pineros AR, Tersey SA, Scheuner D, Mastracci TL, et al. Adiponectin receptor fragmentation in mouse models of type 1 and type 2 diabetes. Archives of Autoimmune Diseases. 2020; 1(1):3-13.
37. Pugia MJ, Jortani SA, Basu M, Sommer R, Kuo HH, Murphy S, et al. Immunological evaluation of urinary trypsin inhibitors in blood and urine: role of N-\& O-linked glycoproteins. Glycoconjugate Journal. 2007 Jan 1;24(1):5-15.

38. Pugia MJ, Ma R, Vella A, Jortani JA, Rosner $M H$, Basu $M$, et al. Uristatin Assay for Prediction of Renal and Other Clinical Events. Part 4 In Inflammatory Pathways in Diabetes: Biomarkers and Clinical Correlates. Pugia MJ, Ed. Cham, Switzerland, Springer, 2015; $127-190$

39. Jortani SA, Pugia MJ, Elin RJ, Thomas M, Womack EP, Cast T, et al. Sensitive noninvasive marker for the diagnosis of probable bacterial or viral infection. Journal of Clinical Laboratory Analysis. 2004;18(6):289-95.

40. Pugia MJ, Sommer R, Corey P, Anderson L, Gleason S, Jortani SA, et al. The uristatin dipstick is useful in distinguishing upper respiratory from urinary tract infections. Clinica Chimica Acta. 2004 Mar 1;341(1-2):73-81.

41. Zhu Q, Jiang $G$, Chute $C G$. Profiling structured product labeling with NDF-RT and RxNorm. Journal of Biomedical Semantics. 2012 Dec 1;3(1):16. 